\title{
As "pedras" no caminho do conhecimento em um curso on-line: um estudo de caso*
}

Liane Dal Molin Wissmann ${ }^{1}$

UNIJUÍ

O uso de ferramentas tecnológicas no ensino-aprendizagem de línguas é uma realidade. No entanto, há que se convir que se trata de uma realidade um tanto nova e que necessita de esforços no que tange à pesquisa e desenvolvimento. Este trabalho buscou fazer uma breve reflexão sobre a mídia ligada ao uso da tecnologia e a realidade encontrada por professores/pesquisadores ao utilizaremse desse componente nos processos de ensino-aprendizagem. Utilizando como corpus os $\operatorname{logs}^{2}$ do Programa de Língua Inglesa para Professores de Inglês de Escolas Públicas, executado pela PUCSP, a pesquisa mapeou 561 ocorrências de palavras estratégicas (como problems, difficult, afraid e algumas negativas universais como never e didn't) que permitissem identificar as dificuldades encontradas, tanto por professores quanto por alunos que decidem embarcar numa experiência que se utiliza de Computer Assisted Language Learning - CALL. ${ }^{3}$

The use of technological tools in language teaching-learning is already a reality. This situation, however, is new and demands efforts regarding research and development. This work proposes a brief reflection about the media associated to the use of technology and the reality found out by teachers/researches that utilize this component in his/her teaching/learning. The corpus consists of the logs of English Language Program for English Teachers for Public Schools, carried out by PUCSP. Some 561 words (such as problems, difficult, afraid and universal negatives like never and $d_{i d n ' t}$ ) aimed at identifying teachers and learners difficulties into Computer Assisted Language Learning experience were located.

* Gostaria de registrar a imprescindível colaboração do Prof. Ms. Hamilton de Godoy Wielewicki, meu orientador, que contribuiu de forma relevante para a construção deste trabalho. Também gostaria de agradecer a Profa. Dra. Lucia Rottava pelas sugestões e leitura prévia deste trabalho.

${ }^{1}$ Aluna do Mestrado em Letras, área Estudos Lingüísticos, sub-área Linguagem, Cultura e Sociedade - UFSM.

2 O termo refere-se à gravação da "conversa/discussão" ocorrida durante as sessões de chat, ou sala de aula on-line.

${ }^{3}$ O termo CALL refere-se ao uso do computador na condição de auxílio, meio ou ferramenta na aprendizagem de línguas, podendo ser traduzido como "aprendizagem de línguas auxiliada por computador". 


\section{Introdução}

O uso de tecnologia como suporte/meio para o ensinoaprendizagem tem sido visto como essencial para a inclusão das pessoas no que se convencionou chamar de mundo globalizado ou "aldeia global", devido ao acesso facilitado e imediato à informação e comunicação com o mundo, via rede mundial de computadores.

Surgem ofertas de todos os tipos de cursos via Internet, para atender às mais diversas necessidades e públicos, vendendo a imagem de que a tecnologia é a chave para a solução de qualquer problema. Entretanto, pesquisas têm mostrado que nem sempre essa tecnologia é a melhor opção para o professor e/ou o aluno, uma vez que demanda tempo considerável para o planejamento e organização de atividades e para a adaptação ao novo meio, bem como exige um aluno mais autônomo e comprometido com a construção do seu saber (WARSCHAUER, 1996, 1997; BARRETO, 2000; FAUSTINI, 2000; LACOMB, 2000; MOTTAROTH, 2000; BRAGA E COSTA, 2001; PAIVA, 2001a, 2001b).

Passada a euforia inicial de ensinar/aprender através desse novo meio, vem a realidade de enfrentar um desafio que nem sempre é fácil de resolver, que é o como fazê-lo. É preciso considerar, além de limitações relacionadas a hardware e software, fatores humanos que, geralmente, não são passíveis de previsão. Assim, a partir dos logs coletados junto a um curso on-line que se utilizou de ferramenta síncrona ${ }^{4}$ (chat) para viabilizar a comunicação entre todos os participantes do curso e discussão dos conteúdos, buscamos fazer, inicialmente, um levantamento quantitativo de palavras que poderiam denotar algum tipo de problema ou dificuldade enfrentados tanto pela professora quanto pelos alunos e algumas negativas universais, obtendo a seguinte relação: problem(s), doubt(s), lost, lose, worry, difficult(ies), wrong, afraid, mistake(s), never, can't, couldn't, wouldn't, didn't. Esse procedimento teve como justificativa o extenso número de páginas a serem analisadas (aproximadamente 455). Logo a seguir, após identificarmos as 561 ocorrências dessas palavras, passamos para a análise qualitativa das mesmas e comparamos os resultados obtidos com as respostas de um questionário aplicado aos alunos no final do curso, com o intuito de

${ }^{4}$ É necessário que os alunos estejam on-line ao mesmo tempo. 
mapear quais seriam as "pedras no caminho" do conhecimento em um curso on-line.

\section{O uso da tecnologia na educação e no ensino de língua estrangeira (LE): "Pedras no caminho"}

Muitas são as expectativas que se criam em torno da tecnologia e dos benefícios e "soluções" advindas dela. Uma das áreas "alvo" dessa publicidade é, sem dúvida, a educação. Entretanto, a realidade tem mostrado que "ironicamente, ao que parece, precisamos muito mais de investimentos humanos" do que tecnológicos ou em equipamentos (WISSMANN \& WIELEWICKI, 2002, p.145).

Concordamos com Brady (2001) quando chama a atenção sobre o senso comum "fabricado" pela própria indústria da tecnologia de que, através dela, pode-se estar a qualquer tempo, em qualquer lugar ("anytime, anywhere"). A autora salienta que esse tipo de promessa fica patente quando nos deparamos com campanhas publicitárias nas quais a Microsoft pergunta-nos: "Onde você deseja ir hoje?"5 (op. cit., p. 347), e que reforçam a crença do poder ilimitado da tecnologia. Nesse sentido, o problema torna-se mais grave quando esse tipo de construção estendese até o ensino sob forma de Educação a Distância (EAD) porque, segundo Brady, professores e aprendizes vão deparar-se com fatores que não correspondem à propaganda acima referida, dentre os quais o acesso à tecnologia, no qual tempo e espaço continuam a impor limites, e a percepção do aluno com relação ao papel do professor, que pode parecer invisível aos olhos dos mesmos. Dessa maneira, aquele aluno que usa regularmente a tecnologia terá mais chances de sucesso em um curso a distância do que aquele que possui acesso limitado e/ou não desenvolveu domínio no uso dela.

Gresham (1999) ressalta que o acesso desigual à tecnologia pode ser um entrave ou barreira para que o aluno desenvolva aquilo que imaginou, podendo interferir no seu desempenho e também na manutenção das metas pedagógicas estipuladas. Dessa forma, o uso de tecnologias em sala de aula é positivo, desde que o professor esteja

5 "Where do you want to go today?" 
alerta para alguns "perigos", tais como: incorporar tecnologia a um curso de forma não crítica ou usá-la sem critérios compatíveis com os objetivos dos alunos. O autor recomenda, portanto, que o professor inclua os alunos no processo de planejamento da disciplina e compartilhe com eles os objetivos pedagógicos e tecnológicos do trabalho a ser realizado.

Horton (2000, p. 517 apud WEYERSBACH, 2002), apresenta uma relação de sugestões a serem seguidas na hora de escolher ou elaborar um curso on-line:

limitar a quantidade e a sofisticação de tecnologia necessária para o curso; fornecer instruções claras; levar os alunos a utilizarem o sistema antes do início do curso; planejar suporte técnico; estabelecer um teste de entrada para que os alunos possam verificar se estão aptos a fazerem parte do curso; fornecer instruções completas do computador; preparar formas de apoio para eventuais dúvidas dos alunos; e organizar formas suporte entre os membros da equipe (WEYERSBACH , 2002, p.22).

No que tange ao ensino de LE, é preciso reconhecer que, como qualquer outra disciplina do currículo, ela também tem aproveitado os benefícios que a tecnologia trouxe para a educação. Warschauer \& Healey (1998) defendem o uso de computadores na sala de aula de LE em função de algumas características, tais como: múltiplas formas de práticas com feedback; possibilidade de oferecer um ensino mais individualizado numa classe de grande porte; trabalhar em pares ou pequenos grupos em projetos, assim como trabalhar de forma colaborativa ou competitiva; existência do fator diversão; variedade de recursos disponíveis e adequáveis aos estilos de aprendizagem; aprendizagem exploratória com um grande número de dados referentes à língua/linguagem e construção de habilidades reais no que diz respeito ao uso do computador.

Entretanto, esse uso não deve ser indiscriminado, como aponta Warschauer (1997), mas seguir algumas diretrizes básicas, quais sejam: considerar cuidadosamente os objetivos e metas a serem alcançados e a adequação da ferramenta escolhida aos propósitos desejados; integrar as atividades propostas num projeto maior dentro do currículo; não subestimar a complexidade advinda do uso do computador; prover ao aluno suporte adequado e suficiente para que possa desenvolver o que foi proposto; envolver os alunos nas decisões, ouvindo suas opiniões e descentralizando o poder do professor no que se refere ao processo de ensino-aprendizagem. 
Ressaltamos ainda a pesquisa de White (1999), para quem principiantes no contexto de Educação a Distância tendem a desenvolver expectativas particulares com relação à auto-instrução, as quais são revisadas e modificadas com o passar do tempo e a construção de experiência no novo contexto. Em geral, acontece uma alteração no que a pesquisadora chama de foco de controle, passando de externo (qualidade dos materiais do curso, qualidade e quantidade de interação com tutores) para interno (motivação, confiança em si mesmo, quantidade de tempo empregado no estudo, persistência). Quando essa alteração não ocorre, pode ser indicativa de diferenças individuais entre os aprendizes, demonstrando que alguns são menos predispostos ou aptos a ajustarem-se a um modelo não convencional de aprendizagem de línguas. Conseqüentemente, a forma como os aprendizes reagem à Educação a Distância pode ser determinante para o sucesso (ou não) nesse tipo de aprendizagem.

Também as pesquisas em CALL, segundo Levy (2001), têm apontado para um ritmo acelerado nas mudanças e inovações tecnológicas; desigualdade em termos de introdução da tecnologia nas escolas e universidades; carência com relação à formação de professores e motivação e metas erradas para a adoção do uso de computadores na sala de aula de LE.

\section{O chat}

Devido ao chat ser o recurso utilizado para viabilizar as discussões entre professor e alunos no curso analisado, cabem aqui algumas considerações sobre o mesmo: ele é uma das ferramentas mais profícuas quando falamos de CALL. A possibilidade de servir de suporte para a comunicação, em tempo real, entre duas ou mais pessoas, independente do lugar em que se encontram, bastando para isso estar conectado à Internet, trouxe novas perspectivas para a educação em geral, e seu uso na sala de aula de língua estrangeira aponta para vantagens no que diz respeito à participação dos alunos, ao uso da linguagem para a comunicação efetiva e para desenvolver a escrita.

Sabbag (2002) lembra que, embora existam semelhanças entre o chat público e o instrucional em relação à alternância de turnos, este último apresenta características próprias, como por exemplo o tipo de linguagem empregada, a forma de interação entre os participantes e 
a obrigatoriedade de participação e discussão de tema pré-selecionado, sem, no entanto, perder o caráter de naturalidade e espontaneidade. Por permitir a visualização da produção, o chat alivia a carga cognitiva sobre o usuário, possibilitando maior aproveitamento do conteúdo ao qual ele está exposto. Assim, o aluno pode ver sua produção sem precisar confiar apenas em sua memória, refletindo sobre o que foi escrito, observando, comparando e, se for o caso, corrigindo.

Warschauer \& Healey (1998) postulam ainda que a linguagem usada em discussões via comunicação síncrona mostra-se mais complexa léxica e sintaticamente do que a discussão face-a-face e, portanto, seria um bom veículo para auxiliar os estudantes a desenvolver e aperfeiçoar a língua alvo.

Alguns estudos ainda chamam a atenção para fatores relevantes, como a possibilidade de uma participação mais eqüitativa de todos os alunos, uma vez que na sala de aula convencional os turnos são alocados, em geral, pelo professor, que, quando o cede, tende a ser para os alunos mais talentosos (FONSECA, 2001), e desenvolvimento das capacidades de refletir, criticar e discursar do aluno, bem como uma postura mais ativa no processo ensino-aprendizagem (MOTTA-ROTH, 2000). Considerando as características da ferramenta e o próprio esforço da professora em propiciar a participação de todos no curso em questão, queremos acreditar que os dados coletados consigam representar não os sentimentos/impressões de poucos, mas da turma como um todo.

\section{O objeto de estudo}

A pesquisa baseou-se no Programa de Língua Inglesa para Professores de Inglês de Escolas Públicas, estruturado em 6 módulos, 4 deles via Internet e 2 presenciais, e executado pela PUCSP, através do Projeto EDULANG, ${ }^{6}$ do

\footnotetext{
6 "O grupo EDULANG integra o projeto Lingüística Aplicada em Contexto Digital, que se caracteriza como um projeto na interface das áreas da Lingüística Aplicada, da Educação a Distância e da Tecnologia Digital." "O projeto está sediado no PPG em Lingüística Aplicada e Estudos da Linguagem - LAEL - da PUC-SP. É integrado por pesquisadores titulados de quatro universidades: A PUCSP, a UNICAMP, a Universidade Federal de Uberlândia e a Universidade de Liverpool, Inglaterra. O Projeto EDULANG é coordenado pela Profa. Dra. Heloisa Collins, que gentilmente possibilitou-me participar como assistente do curso, ministrado pela professora Scheyla Riyadh Weyersbach e com apoio técnico da professora Maria Paula Salvador Wadt.
} 
Programa de Pós-Graduação em Lingüística Aplicada e Estudos de Linguagem - LAEL, e pela Sociedade Brasileira de Cultura Inglesa - São Paulo.

Nosso objeto de estudo foi o Módulo 1, que contou com a participação de uma professora, duas assistentes, e ainda outro sujeito que desempenhou a função de suporte técnico, além dos 37 alunos inscritos. Este módulo, por ser o primeiro do curso on-line, foi precedido por um tutorial-presencial, que teve como objetivo entrosar professora e alunos e também familiarizar os mesmos com o ambiente do curso e suas ferramentas. O curso foi elaborado utilizando o software WebCT, que possibilita, entre outros recursos, a utilização de aulas síncronas, que deram origem ao corpus deste trabalho, e assíncronas. ${ }^{7}$ As aulas síncronas utilizavam como ferramenta o chat e aconteciam em dois momentos semanais, ou seja, terças e quintas-feiras à noite, com uma hora de duração, sendo os alunos divididos em grupo A e grupo B. O horário da noite foi escolhido pelos alunos em função do fato de se adequar às outras atividades por eles desenvolvidas, uma vez que a grande maioria trabalhava até as 23 horas. Embora acontecessem em dois momentos distintos durante a semana, as aulas tratavam do mesmo assunto por dois motivos: o primeiro porque o grupo era muito grande para ser reunido em uma única sala de chat e o segundo porque, caso um aluno não pudesse comparecer em um dia, teria uma segunda chance para fazê-lo em outro.

O referido módulo teve a duração de dez semanas, de julho a setembro de 2002, período no qual desempenhei a função de assistente, com tarefas que incluíram: a) observação do design do curso e discussão sobre possíveis modificações; b) participação nas aulas síncronas (chat) e observação da produção assíncrona; c) acompanhamento da participação dos alunos e preenchimento de tabelas com registros de participação; d) discussões com a professora sobre o progresso e as dificuldades enfrentadas pelos alunos.

Como objetivos gerais do módulo, foi estabelecido que deveria propiciar maior conscientização sobre processos de leitura; melhor desempenho estratégico no que diz respeito a essa habilidade e desenvolvimento de possibilidades criativas para o ensino da mesma.

\footnotetext{
${ }^{7}$ Aulas que não exigem que os aprendizes estejam online ao mesmo tempo.
} 
O chat constituiu-se, então, no espaço privilegiado para a discussão dos conteúdos, dificuldades, troca de informações e, além de tudo, para entrosamento e estreitamento de relações. Foram 8 encontros para cada grupo, sendo o primeiro mais uma experiência do que propriamente uma aula para discussão de conteúdos e que teve o propósito de familiarizar os alunos com a ferramenta. Devido à possibilidade de gravação das sessões de chat, foi possível coletar o corpus para esta pesquisa, armazenando-se um total de, aproximadamente, 455 páginas, que correspondem basicamente às aulas programadas.

Um fato interessante que aconteceu durante o curso é que os alunos faziam questão de receber uma cópia dessas gravações para que pudessem rever com mais cuidado as discussões realizadas, tirar dúvidas ou ter acesso às informações, principalmente quando não podiam participar das sessões de chat. Na maioria das vezes, um dos alunos, que tinha maior intimidade com o uso da Internet e do computador, ficou responsável pela gravação das aulas síncronas; em outras ocasiões, o trabalho era feito por mim, com duas opções: enviava uma cópia não editada das gravações e outra apenas com as discussões centrais da aula, retirando cumprimentos e discussões paralelas, com o objetivo de otimizar a leitura dos arquivos em um tempo mais curto, agilizando o processo.

De forma geral, o chat foi para os alunos uma experiência nova, na qual puderam trabalhar de forma síncrona com a professora, colegas e suporte técnico, trocar experiências e resolver/esclarecer questões relativas ao curso. A partir de questionário aplicado ao fim do módulo 2, elaborado por membros do grupo Edulang e encaminhado sob forma digital pela professora do curso aos alunos, obteve-se um retorno de $74 \%$ dos mesmos, o que permitiu uma visão bastante ampla, do ponto de vista dos alunos, dos aspectos positivos e negativos do curso. Assim, de acordo com esse questionário, pode-se concluir, paradoxalmente, que o chat foi a ferramenta que mais suscitou reclamações e registros de pontos negativos em função de, muitas vezes, perder-se tempo com dúvidas insignificantes ou saudando os colegas. Outro ponto considerado negativo foi o horário das sessões de chat (23h $15 \mathrm{~min}$ e $23 \mathrm{~h} 30 \mathrm{~min}$ ), citado por 6 alunos diferentes, que acabou prejudicando o próprio aproveitamento do curso, em função do cansaço acumulado ao longo do dia ou que se manifestava no dia seguinte. O horário previsto para cada aula era de 1 hora; porém, as discussões se prolongavam até mais tarde, havendo ocasiões em que era encerrada à 01h 30min. A própria 
falta de pontualidade de alguns alunos, ocorrida por motivos diversos, que acabavam por conectar-se ao curso quando já era decorrida metade da aula, terminava por atrasar as discussões e também foi relatada como ponto negativo. Entretanto, o horário das sessões de chat foi negociado com todos os alunos, que sugeriram essas duas possibilidades em razão de outros compromissos e apenas um deles sugeriu, no questionário, que as sessões de chat acontecessem aos sábados ou domingos.

Foram relatados ainda problemas de conexão, sendo que 4 participantes do curso afirmaram que "cai sempre", 10 que "às vezes" e 6 "raramente". Coincidentemente ou não, dos 6 que disseram que raramente perdiam a conexão, 2 utilizavam o computador há cerca de 12 anos, 1 utilizava-o há mais de dois anos, 1 não respondeu e apenas 2 utilizavam-no por um período entre 0 a 6 meses. Esses dados sugerem que os alunos que praticamente não tiveram problemas de conexão foram aqueles que tinham uma certa perícia ou habilidade em utilizar a máquina e os recursos da Internet, ou que possuíam equipamentos mais atuais. Houve ainda quem considerasse a falta de prática ou habilidade em pensar e escrever rapidamente em inglês como um fator negativo, que veio prejudicar o uso do chat nas aulas do curso. Também a impossibilidade de ler e preparar, em tempo hábil, as atividades programadas para discussão, ocasionou a sensação de estar "perdido" no desenrolar das aulas síncronas.

\section{Os sujeitos da pesquisa}

O público alvo do curso constituiu-se de professores de inglês da rede estadual do ABCD Paulista. A partir do questionário aplicado, pudemos fazer o levantamento de alguns dados desses alunos/ professores, que nos possibilitaram uma visão abrangente do público atendido. A faixa etária média dos alunos era de 38 anos, oscilando entre 27 e 54 anos. Daqueles alunos que responderam à questão sobre sua formação acadêmica, 21 eram graduados, sendo 13 licenciados em Letras e 8 em Letras com habilitação em Português/Inglês.

Com relação ao acesso à Internet, 14 alunos afirmaram que já faziam uso dela anteriormente ao curso: 3 alunos a empregavam por um período de 0 a 6 meses, 2 pelo tempo de 6 meses a 1 ano, 5 entre 1 e 2 anos, e 4 utilizavam a Internet por mais de 2 anos. 
Um dado interessante do questionário dizia respeito ao grau de dificuldade encontrado pelo aluno com relação ao fato de não ter a presença física da professora ou dos colegas. Treze alunos apontaram uma certa dificuldade inicial, superada ao longo do curso, 8 não consideraram esse fator como problema e apenas 1 relatou que sentiu muita dificuldade por não ter a presença física da professora ou dos colegas. Cabe ressaltar aqui que, embora a professora não estivesse face-a-face com os alunos, procurava se fazer presente através de outras formas de contato. Assim, como afirma Barreto (2000, p. 179), mesmo diante da idéia de algumas pessoas/órgãos/instituições de que a EAD está "... fundada em materiais supostamente auto-explicativos, parecendo prescindir do trabalho docente, em função do investimento em tecnologia", a realidade tem mostrado que a participação do professor é fundamental, mesmo que se faça de forma virtual.

Outro fator relevante que o questionário buscou identificar foi a capacidade dos alunos de fazer planejamento para cumprir com as atividades propostas, em tempo hábil. Em outras palavras, além do equipamento mínimo necessário para realizar o curso (computador Pentium 133Mhz, com 32Mb de memória, acesso a Internet, etc.), fezse questão de ressaltar a necessidade de o aluno dispor de um mínimo de 4 a 5 horas por semana para garantir a realização das tarefas. Há que se lembrar que durante o período de realização de um curso, seja presencial ou on-line, normalmente ocorrem problemas que não estavam previstos e que podem ser determinantes para a desestabilização de um programa ou uma agenda inicial - e tais problemas de fato ocorreram. Como conseqüência, 12 alunos afirmam terem feito planejamento, mas, por razões diversas, não o mantiveram, 6 atestaram que não fizeram planejamento e apenas 4 confirmam a realização de um planejamento e a manutenção do mesmo.

Embora o tempo mínimo sugerido aos alunos para dedicarem-se ao curso fosse de 4 a 5 horas por semana, a maioria afirmou ter necessitado de 4 a 7 horas. Alguns, porém, utilizaram apenas 3 horas semanais para realizar as atividades propostas e outros precisaram de 8 horas ou mais para concluir suas tarefas. É interessante observar que, daqueles alunos que necessitaram de mais de 11 horas, um não tinha conhecimento de informática nem fazia uso da Internet antes de ingressar no curso e outro a utilizava por um período não superior a 6 meses, acrescido ao fato de que sua graduação não era na língua alvo, o que poderia associar 
problemas de ordem técnica (Internet) à problemas relacionados ao conhecimento da língua estrangeira (Inglês).

Verificando o item relacionado à efetiva realização das tarefas, ainda é possível acrescentar o dado de que os alunos que mais dispenderam tempo com a realização das atividades também foram aqueles que imprimiram todo o material do curso para só então respondê-lo. Esse fato pode estar relacionado, segundo Wielewicki (2003), com a crença, por parte dos professores, de que a leitura na tela do computador é mais lenta que em materiais impressos. Segundo o autor, colaboram para isso a falta de conhecimento do ambiente digital e de experiência em ler nesse meio, e fatores afetivos como, por exemplo, ansiedade, até porque computadores e Internet são eventos relativamente recentes na vida acadêmica.

Outro fato importante a salientar é que, dos 22 alunos, apenas 1 não possuía computador em casa, viabilizando sua participação através dos computadores da escola e de colegas. Dos 21 restantes, 4 utilizavam também o computador da escola e 1 aluno utilizava o computador de amigos para realizar suas tarefas.

\section{Metodologia}

O corpus deste trabalho foi constituído a partir dos logs das aulas síncronas realizadas no módulo 1, relativos à discussão das tarefas e conteúdos, que totalizaram aproximadamente 455 páginas de material transcritas neste trabalho de forma literal. As aulas foram automaticamente gravadas na memória do curso pelo software educacional utilizado, serviram de material para análise, observação e reflexão, e foram confrontadas com os questionários avaliativos preenchidos ao final do módulo 2, em busca de respostas sobre quais são as maiores dificuldades dos alunos e o que pode constituir-se em empecilho para o desenvolvimento de uma proposta de curso nessa modalidade.

Tendo essas questões como alvo, procuramos fazer um levantamento das palavras que poderiam indicar algum tipo de dificuldade, tais como algumas negativas universais (never, can't, couldn't, wouldn't, didn't), e também palavras chaves tais como problem(s), doubt(s), lost, lose, worry, difficult(ies), wrong, afraid e mistake(s). Esse levantamento preliminar deu-se a partir da análise do primeiro encontro no chat, ocorrido no dia 31 de julho de 2002, e do último encontro, ocorrido no 
dia 26 de setembro do mesmo ano. Considerando-se o grande volume de dados a ser coletados, foi necessário utilizar para essa análise o programa Concapp Concordance Browser and Editor for Windows. Esse software, através de um ou múltiplos arquivos, faz o levantamento de uma determinada palavra no corpus escolhido, relacionando-a tantas vezes quantas aparece no texto e identificando quais são as palavras que a antecedem e/ou precedem. Essa característica foi de grande proveito para a pesquisa, uma vez que possibilitou a racionalização e agilização no levantamento dos dados. Entretanto, devido às limitações no que tange ao número de palavras antecedentes e/ou precedentes possíveis de elencar, tivemos que recorrer à opção de "localizar palavra" do editor de textos do Word para termos acesso às discussões anteriores à palavra em questão e poder situá-la no contexto em que a mesma ocorreu. Outro cuidado que tivemos na tabulação dos dados foi o de separar as ocorrências originadas dos alunos das ocorrências originadas da professora ou suporte técnico, por considerarmos que apresentam diferenças significativas com relação à intenção e significado, mesmo no emprego de itens lexicais iguais. Neste texto, pelo espaço reduzido que dispomos, apresentaremos apenas os dados de maior significância.

\section{Resultado da análise dos dados}

De acordo com a proposição inicial deste trabalho, iniciamos a análise do corpus buscando observar, classificar e interpretar os dados, tomando o cuidado de fazê-lo de forma a separar as ocorrências que se referiam à fala dos alunos da fala da professora e do suporte técnico, por considerar que cada um deles desempenha um papel diferenciado no processo ensino-aprendizagem e, portanto, merecem um olhar atento, que respeite e considere essa diferença. Dentro do que poderíamos chamar uma postura relativamente "tradicional" dos alunos, pudemos identificar o lugar comum de alguns que, em tendo dificuldades, perguntas, dúvidas, vêem no professor aquele que tem a fórmula, a receita certa, as respostas. É preciso ressaltar que muito tem sido feito para uma mudança nesse "padrão de comportamento". No entanto, é inegável que ainda hoje existe uma expectativa em torno do saber do professor (o que me parece até certo ponto correto, uma vez que é um profissional que teve formação específica para tal) e das "respostas" que 
ele possa dar aos problemas e dúvidas dos alunos. Essa postura se reproduziu ao fazermos o levantamento do número de ocorrências da palavra "problem(s)" nos diálogos gravados do curso. De 182 ocorrências dessa palavra, 144, ou seja, 79\%, foram feitas pelos alunos e apenas 38, ou 21\%, foram feitas pela professora ou pelo suporte técnico. Confirmando a postura do aluno ainda como dependente do professor e que tem nele a figura central do ensino-aprendizagem, temos os dados que indicam que das passagens nas quais verificou-se a oferta de ajuda diante de algum problema, 12 ofertas partiram da professora e do suporte técnico e apenas 4 foram oferecimentos de ajuda de um colega ao outro. Por outro lado, podemos confirmar o papel do professor como um facilitador da aprendizagem, atento para os diversos aspectos da fala de um aluno e buscando identificar problemas e auxiliar na sua superação. Esse dado reforça o estudo de Braga e Costa (2000), no qual as autoras, após compararem dois tipos de aula, quais sejam, presencial e virtual, concluíram que nesta última (,) tanto professor quanto alunos (,) "optaram por uma interação mais centrada no professor...", revelando que

... as mudanças nos padrões de interação pedagógica não ocorrem de forma abrupta, mas sim de forma gradual, à medida que os sujeitos envolvidos se sintam mais familiarizados com as novas possibilidades desse novo meio e entendam de forma mais clara as suas especificidades. (op. cit., p. 78).

De acordo com os dados, constatamos que o uso mais freqüente da palavra "problem(s)" foi relacionado à conexão e a problemas técnicos ou com o computador (70 ocorrências). Outro dado interessante e também positivo é de que apenas 7 menções a problemas estavam relacionados ao uso das ferramentas do curso, o que pode atestar a eficiência dos passos sugeridos por Weyersbach (anteriormente referidos), e que foram seguidos no curso investigado neste estudo.

Também levantamos um número de 7 menções relacionadas à algum problema em realizar tarefas propostas pelo curso, como por exemplo a dificuldade em ler textos em outras línguas, em especial um texto em alemão, e a impossibilidade de acessar algum site sugerido em uma das tarefas do curso. Cabe ressaltar aqui a necessidade de verificações regulares com relação aos sites indicados aos alunos, garantindo que eles terão apenas problemas relativos à conexão e não à páginas que já expiraram ou estão em manutenção, evitando perda 
de tempo e frustrações desnecessárias. Essa era uma medida que a professora do curso sempre tomava, tanto ao sugerir um site quanto ao divulgar outros endereços que partiam da sugestão dos próprios alunos, o que aconteceu por várias vezes, quando foi proposta a criação de um banco de dados, com sugestões de sites interessantes para utilizar em sala de aula, bem como de atividades a serem elaboradas/ desenvolvidas a partir deles.

Salientamos ainda que, das 182 ocorrências da palavra problem(s), 21 ocorrências relatavam justamente o contrário do que se espera da palavra, ou seja, a não existência de problemas: no problem.

Com relação à palavra afraid, encontramos apenas 5 aparições, 2 ditas pela professora, uma solicitando esclarecimento sobre a apreensão/ medo do aluno e outra tranqüilizando-o. De parte dos alunos, apenas um utilizou a palavra de forma significativa, ou seja, manifestando sua insegurança ou receio em realizar tarefa proposta pelo curso.

Outra palavra que fez parte do levantamento foi difficult(ies), com 45 ocorrências. Nesse caso, tivemos dados mais representativos (14 ocorrências) com relação à dificuldade dos alunos em realizar determinada tarefa proposta pelo curso, no caso, leitura de textos em outras línguas, leitura de textos com poucos cognatos, encontrar textos adequados para os seus próprios alunos, entre outros. Referente à pesquisa de sites que possam adequar-se à realidade dos alunos nas escolas de ensino fundamental e/ou médio, citada por 3 alunos como uma tarefa na qual encontraram dificuldades, é preciso lembrar que a busca de material na rede não se constitui em atividade fácil nem para aqueles que já têm uma certa habilidade em reconhecer, entre um extenso número de informações e sugestões, o que pode ser relevante, provir de uma fonte segura e ainda adequar-se ao "gosto" dos alunos (preferências, faixa etária, etc).

As demais ocorrências da referida palavra pulverizaram-se entre opções como dificuldade no uso de ferramentas do curso, conexão e habilidade para digitar. Essas ocorrências podem ser consideradas dificuldades de cunho técnico e que, com o passar do tempo e o crescimento da intimidade no manejo da máquina e das ferramentas oferecidas pelo curso, tenderiam a diminuir ou até desaparecer.

A palavra mistake( $(s)$ foi encontrada 12 vezes e estava relacionada a uma colocação de certa forma polêmica, de parte de um dos alunos, que afirma: 
$\mathrm{A}^{8} 29>>$ The teacher is never wrong. They are always trying a new experiment to turn the classes better than the last class. (...)

e, a partir daí, se estabelece uma discussão sobre essa afirmação, na qual levantamos 3 ocorrências da palavra mistake feita por alunos e 2 feitas pela professora, afirmando que errar é da natureza humana e, portanto, também dos professores. Mais uma vez, encontramos somente o professor esclarecendo dúvidas e oferecendo ajuda.

As palavras lost/lose foram citadas 44 vezes e foram representativas quando os alunos quiseram relatar/informar a causa que os fazia estar/ ter perdido algo. Entre essas causas podemos citar: não saber como agir no chat; sentir-se perdido porque chegou atrasado ou porque não realizou a tarefa sobre a qual girava a discussão; ao escolher sites na Internet para trabalhar em grupo ou com seus próprios alunos; devido às muitas ferramentas oferecidas pelo curso; ou na discussão realizada no chat, devido à perda de conexão. Essa última refere-se ao problema que ocorre em função de que, quando o aluno perde a conexão e sai do chat, ao conectar-se novamente sua tela retorna vazia, ou seja, as discussões anteriores desaparecem e ele passa a recebê-las somente a partir da última conexão, o que se constituiu num entrave para aqueles que enfrentavam problemas de conexão instável, pois perdiam parte ou toda uma discussão feita na aula. Essa restrição deu-se apenas em função do tipo de software utilizado. Uma das formas encontradas para minimizar o problema foi, como já relatamos anteriormente, enviar os logs das aulas para todos os alunos, propiciando, àqueles que perderam alguma parte da discussão, o esclarecimento de suas dúvidas e àqueles que não participaram da aula, ter oportunidade de se inteirar do andamento das atividades e dos encaminhamentos dados.

A palavra wrong foi detectada por 19 vezes e esteve relacionada 6 vezes a uma discussão sobre o direito do professor errar. Também esteve ligada a pedidos de esclarecimento de alunos aos seus colegas sobre algo que julgavam estar errado ou a manifestações sobre o uso das ferramentas do curso e habilidade para digitar, dentre outras.

\footnotetext{
${ }^{8}$ A letra "A" é utilizada neste trabalho como abreviatura da fala de aluno, seguida de um número que corresponde à ordem em que o mesmo se encontrava na lista de chamada do curso, no Módulo 1. Para as "falas" da professora usou-se a abreviatura "P" e, para o suporte técnico, "ST".
} 
A $1>$ A 4, don't worry if you are writing wrong.!!! Only write what you are thinking!!!

As palavras worry e doubt foram 2 exceções, uma vez que utilizadas, na maioria das vezes, pela professora ou pelo suporte técnico.

Das 37 ocorrências da palavra worry, 18 foram feitas por alunos e 19 pela professora, sendo que 24 delas foram com o intuito de tranqüilizar um colega/aluno sobre algum fato que o deixava aborrecido. As outras ocorrências foram em virtude de estar aborrecido devido a problemas de conexão, dificuldade na realização de uma tarefa proposta pelo curso ou problemas técnicos, ou a palavra foi utilizada para solicitar esclarecimentos ao colega sobre o porquê de ele estar aborrecido, informar aluno sobre problema e esclarecer dúvida/ oferecer ajuda.

Já a palavra doubt apareceu 78 vezes, sendo que em 25 delas foi utilizada por alunos e 53 pela professora ou pelo suporte técnico. Novamente aqui se destaca o papel do professor como orientador/ auxiliador, com 25 ocorrências nas quais ele esclarece alguma dúvida e/ou oferece ajuda, contra apenas 1 ocorrência desse tipo advinda de aluno.

A 10 >>People, if you have anydoubts about Unit 3 and if you would want a help, please send a e-mail for me. I can motivate you to do your lessons, ok? My personal e-mail is: xxxxxxx@brfree.com.br

Também encontramos 18 ocorrências da parte da professora ou suporte técnico solicitando algum tipo de esclarecimento com relação à dúvidas que tinham surgido e apenas 5 da parte dos alunos:

ST >>I think I am going to bed too! A 33, is there any doubt you have about technical aspects?

$\mathrm{P}>>$ I just wanted to know where you are in Unit 2, A 6. If you have any doubt, etc. The same I asked your colleagues.

As demais ocorrências não são representativas e relatam e/ou informam algum problema ou tranqüilizam o aluno sobre algum fato, sem, no entanto, se referir à problemas com o curso especificamente.

A seguir passamos para as negativas em algumas de suas formas universais, para analisá-las em suas aparições nos logs gravados. 
A expressão never foi encontrada 14 vezes. Porém, não apresentou dados relevantes à análise, com exceção de duas vezes em que foi utilizada por aluno para informar nunca ter realizado atividade semelhante à proposta e a estratégia que empregou ao se deparar com dificuldade.

As palavras can't e couldn't foram detectadas 24 vezes e utilizadas pelos alunos por 5 vezes para comunicar a impossibilidade de realizar algo, devido a problemas técnicos ou de equipamento, e outras 5 vezes comunicando a mesma impossibilidade, porém devido a problemas individuais. Aqui temos dois extremos: no primeiro exemplo, o aluno que não realizou as tarefas/leituras necessárias para poder participar da discussão com conhecimento de causa:

\section{A $26>>$ A 28 today wecan't discuss about text because I didn't read all the texts.}

No segundo exemplo, o esforço de outro que, apesar do horário avançado e outros tantos entraves que possamos imaginar para a situação, fez o possível para participar da aula, mesmo que na casa do vizinho, utilizando o seu equipamento. É interessante salientar que, de acordo com o registro do log, já passava da 01 hora da manhã ("A 22" left leit06_Room1. Fri Sep 27, 2002 01:06).

A 22 >>Thanks teacher, Ican't stay anymore, my neigbord must go to the bed.

Já para a palavra didn't, foram encontradas 98 ocorrências, das quais 91 foram elaboradas pelos alunos $(92,8 \%)$ e 7 pela professora ou suporte técnico $(7,1 \%)$. Do total de 98 ocorrências, 36 foram relacionadas à realização de tarefas propostas pelo curso: 11 não fizeram o trabalho proposto; 10 não leram todos os textos; 7 não tiveram tempo para terminar as atividades; 2 tiveram problemas com o texto em alemão; 1 não ligou a palavra ao seu significado; 3 não encontraram sites adequados; 1 não soube o que fazer com o site encontrado; e 1 não decidiu qual o tema que abordaria na realização de uma atividade proposta. Como percebemos, várias são as citações referentes à falta de tempo ou à não realização de todas as tarefas propostas. Porém, nenhuma aponta como causa a insuficiência de explicações. Aqui dois fatores são importantes lembrar: $1^{\circ}$ ) que o público atendido foi composto de professores que atuam na rede pública e que utilizam 
um $3^{\circ}$ ou $4^{\circ}$ turno, além dos finais de semana, para realizar o curso, e que esses professores também possuem vida pessoal, o que exige um bom planejamento ou, no mínimo, disciplina, para dar conta das atividades programadas no tempo determinado; $2^{\circ}$ ) a necessidade de prover explicações claras e detalhadas para que o aluno, mesmo longe da professora, não tenha que "decifrar" o que lhe estão exigindo. Nesse sentido o curso oferecia um cronograma geral de todas as atividades de cada unidade, estimando ainda o tempo necessário para a realização de cada tarefa, informando ao aluno o prazo para a entrega da mesma e, à parte, um calendário no qual o aluno tinha acesso, selecionando o dia de seu interesse, do que estava programado, ou seja, aula no chat, início de um módulo, prazo final de entrega de uma atividade, etc.

As demais ocorrências fazem referências à conexão, problemas técnicos ou com computador, uso de ferramenta do curso e apontam problemas específicos, tais como o fato de o aluno não ter lido o texto porque estava um pouco perdido; não ter assistido ao filme a que se referiram os colegas; esclarecer que não teve intenção de ser irônico com outro colega.

Finalizando, ainda levantamos as ocorrências da palavra "wouldn't". No entanto, atipicamente, unicamente a professora fez uso da mesma, por 3 vezes, com a finalidade de pedir esclarecimentos aos alunos.

\section{Conclusão}

É inegável que a tecnologia é um produto e, como tal, depende de propaganda e de consumo. No entanto, muitas vezes lhe é atribuído um poder invencível, como se pudesse, sozinha, resolver todos os problemas que temos. Essa idealização é particularmente perigosa quando se trata de tecnologia aplicada à educação ou ao ensino de línguas. Sua utilização nessa área tem mostrado, sistematicamente, que ela constituise somente em mais um meio, e que os esforços empregados por professores e alunos é que são essenciais para o sucesso do ensinoaprendizagem. Dessa forma, concordamos com Barreto (2000, p. 184), quando afirma que a idéia de uma $\mathrm{EAD}$ que "aponta para o esvaziamento do trabalho docente, através da articulação das dimensões (...) que sustentam as 'novas tecnologias', enquanto metonímia a serviço da racionalidade instrumental", só pode ser concebida como errônea, não 
se sustentando ao longo de uma experiência de ensino nessa modalidade. O professor é, sem dúvida alguma, fator importante para o sucesso de um curso on-line, pois, em geral, é dele a responsabilidade pela unidade dos conteúdos, escolha das atividades, resolução dos problemas e pela cooperação dentro do próprio grupo. Nesse sentido, professor e alunos devem estar unidos para empregar esforços de forma conjunta, buscando o sucesso de todos como grupo, sendo que esses esforços são de toda ordem: cognitivos, físicos, psicológicos e materiais.

Outro fator que influencia sobremaneira o andamento/ aproveitamento de um curso on-line é de ordem técnica. Embora muito tenhamos avançado no sentido de qualificar e quantificar a base física necessária para a viabilização e a conexão à Internet em nosso país, um dos problemas mais freqüentes enfrentados pelos alunos foi justamente o de conexão nas aulas síncronas (chat). Problemas com o próprio computador também se fizeram presentes nesse percurso. Talvez pela própria falta de habilidade e treino no uso da máquina, ou por equipamentos absoletos, os alunos, por muitas vezes, não conseguiram salvar sua produção, perderam seus trabalhos, tiveram sua máquina "trancada" e tantos outros problemas dessa ordem.

Superados esses entraves iniciais, o aluno tem a sua frente o desafio de lidar com as ferramentas síncronas e/ou assíncronas oferecidas pelo curso. Apesar de existir um treinamento pré-curso para ambientar os alunos com a interface que irão encontrar e todas as suas possibilidades e recursos, é no uso efetivo deles que surgem as dúvidas e que aparecem as falhas. Nesse sentido, foi de suma importância prever um suporte técnico na primeira etapa do curso, dedicado a atender aos alunos com esse tipo específico de problema, ou seja, atendendo àqueles que têm dificuldades, de forma a não prejudicar outros que já entraram no "ritmo", viabilizando também o trabalho da professora, que fica liberada para desenvolver os conteúdos de forma adequada.

No caso específico desse curso, cabe salientar que os alunos não tiveram maiores problemas em realizar as tarefas, devido à natureza ou suficiência das explicações. A dificuldade dos alunos para concretizar algumas atividades foi pelo próprio desafio de empregar estratégias que lhes eram novas, como, por exemplo, ler textos em outras línguas, buscando extrair a idéia geral a partir de fotos, meio em que eram vinculados, conhecimento prévio e cognatos; ou buscar sites adequados para o uso em sala de aula e propor atividades a serem desenvolvidas 
a partir deles. Além dessas dificuldades, ainda houve outras três, basicamente individuais, ou seja, falta de tempo e/ou organização, ocorrência de imprevistos que impossibilitaram ao aluno cumprir os prazos previstos para entrega dos trabalhos e não estar inteirado do assunto sobre o qual versava a aula.

Pode-se perceber também que os alunos ainda buscam no professor a solução de seus problemas, pouco ou nunca recorrendo aos seus colegas, mesmo quando eles demonstraram ter condições de ajudar. O professor segue, na visão dos alunos (que também são professores), como a figura central do processo de ensinoaprendizagem. O papel de esclarecer dúvidas e oferecer auxílio foi, nesse caso, preponderantemente do professor. Por outro lado, demonstra a necessidade de que ele esteja preparado e atento para responder a esses apelos, que não são poucos.

Este estudo reforça a idéia de que o uso da tecnologia requer uma formação específica do professor, que deverá estar apto a lidar com muitos desafios e problemas que nem sempre são passíveis de previsão e planejamento. Também aponta para a racionalização do emprego das novas ferramentas possibilitadas pela Internet, em que pese a influência de seus pontos negativos e positivos para a viabilização de metas e objetivos. Nesse sentido, aluno e professor devem estabelecer uma relação marcada pela colaboração, respeito, solidariedade e responsabilidade para que, como alguém já disse, as "pedras" do caminho sejam utilizadas como degraus para alcançar o sucesso do grupo.

\section{Bibliografia}

BARRETO, R. G. Ensino a Distância: uma tentativa de aproximação. In: LEFFA, V. J. (Compilador). TELA - Textos em Lingüística Aplicada, publicação eletrônica da Revista Linguagem \& Ensino, Pelotas (RS): EDUCAT, 2000.

BRADY, L. Fault lines in the terrain of distance education. Computers and Composition, v. 18, p. 347-358, 2001. (**)

BRAGA, D. B.; COSTA, L. A. O computador como instrumento e meio para o ensino/aprendizagem de línguas. Trabalhos em Lingüistica Aplicada, n. 37, p. 61-81, jan/jun 2000. 
FAUSTINI, C. H. Educação a Distância: o trabalho interativo e a aprendizagem colaborativa na busca pela autonomia. In: LEFFA, V. J. (Compilador). TELATextos em Lingüística Aplicada, publicação eletrônica da Revista Linguagem \& Ensino, Pelotas: EDUCAT, 2000.

FONSECA, L. Alocação de turnos em salas de chat e em salas de aula. In: MENEZES, V. (Org.). Interação e aprendizagem em ambiente virtual. Belo Horizonte: Faculdade de Letras, UFMG, 2001.

GRESHAM, M. The new frontier: conquering de World Wild Web by mule. Computers and Composition, v. 16, p. 395-407, 1999. (**)

HORTON, W. Designing web-based training. US: John Wiley \& Sons. 2000.

LACOMB, I. A. Navegando e aprendendo: reflexões sobre um curso de inglês via rede mundial de computadores. Dissertação de mestrado. PUC - SP. 2000. Disponível em http://lael.pucsp.br/lael/teses/. Acesso em 20 de janeiro de 2003.

LEVY, M. CALL in context: moving the CALL research agenda forward. In: CARMAGNANI, A. M.; GRIGOLETTO, M. Inglês como lingua estrangeira: identidades, práticas e textualidade. English as a foreign language: identity, practices and textuality. São Paulo: Humanitas/ FFLCH/USP, 2001, p. 179-194.

MOTTA-ROTH, D. De receptador de informação a construtor de conhecimento: o uso de chat no ensino de inglês para formandos de Letras. In: LEFFA, V. J. (Compilador). TELA - Textos em Lingüistica Aplicada, publicação eletrônica da Revista Linguagem \& Ensino, Pelotas (RS): EDUCAT - Editora da Universidade Católica de Pelotas, 2000.

PAIVA, V. L. M. de O. Aprendendo inglês no ciberespaço. In: MENEZES, V. (Org.). Interação e aprendizagem em ambiente virtual. Belo Horizonte (MG): FALE/POSLIN/UFMG, 2001a, p. 270-305.

PAIVA, V. L. M. de O. A WWW e o Ensino de Inglês. In: Revista de Lingüística Aplicada, v. 01, n. 1/2001, Faculdade de Letras da UFMG, p. 93-116, 2001 b.

SABBAG, M. do C. O chat e a percepção lingüistica em um curso de inglês on-line. Dissertação de mestrado. PUC - SP. 2002. Disponível em http:// lael.pucsp.br/lael/teses. Acesso em 20 de janeiro de 2003.

WARSCHAUER, M. Comparing face-to-face and eletronic discussion in the second language classroom. CALICO Journal, v. 13, n. 2, p. 7-26, 1996. Disponível em http://www.gse.uci.edu/markw/comparing.html. Acesso em 03/11/2002. 
WARSCHAUER, M.; HEALEY, D. Computers and language learning: an overview. Language Teaching. v. 31, p. 57-71, 1998. Disponível em http:/ /www.gse.uci.edu/markw/overview.html. Acesso em 03/03/2002.

WEYERSBACH, S. R. Curso de inglês negociado no contexto digital da Internet: relato de uma experiência. Dissertação de mestrado inédita. PUC - SP, 2002.

WHITE, C. Expectations and emergent beliefs of self-instructed language learners. SYSTEM, v. 27, p. 443-457, 1999.

WIELEWICKI, H. G. Reading and the internet: teachers' and students' beliefs. Trabalho apresentado no XVII ENPULI - A interculturalidade no ensino de Inglês. Florianópolis (SC), 06 a 10 de abril de 2003.

WISSMANN, L. D. M.; WIELEWICKI, H. de G. Ensino à distância como apoio para a formação de professores de língua estrangeira - inglês. Formas e Linguagens. Ijuí (RS): Editora UNIJUÍ, v. 1, n. 2, p. 125-149, abr./jun. 2002.

(**) Estes artigos estão disponíveis em http://www.periodicos.capes.gov.br/ 